\title{
A case for cold-based continental ice sheets - a transient thermal model
}

\author{
Jan T. Heine and David F. MeTigue \\ Department of Geological Sciences and Quaternary Research Center, University of Washinglon, Seallle. Wiashington 98195, U.S.A.
}

\begin{abstract}
A finite-difference numerical model is used to simulate the temperature profile at the center of an ice sheet throughout the course of a glaciation. The ice sheet is gradually built to a thickness of $3000 \mathrm{~m}$ over about 10000 years, starting on permafrost. A geothermal heat flux is applied at large depth. For an initial surface temperature of $-12.5 \mathrm{C}$, our model shows that basal melting occurs 72000 years after the onset of the glaciation. The important parameters determining the basal temperatures are the initial temperature of the ice and substrate, the rate of downward advection of cold ice and, to a lesser extent, the thickness of the ice sheet. The growth history of the ice sheet does not significantly influence the time at which basal melting occurs. Our results show the possibility that the central parts of the continental ice sheets were cold-based for a significant part of their existence. Heating due to the geothermal heat flux cannot account for basal melting during most or all of a glacial cycle. These results may help to explain the existence of preserved land forms under the ice sheets.
\end{abstract}

\section{INTRODUCTION}

The base of an ice sheet is either frozen to its bed coldbased or at the pressure-melting point warm-based). A cold-based ice sheet moves by internal deformation and causes little erosion at its bed, while a warm-based ice sheet moves by both internal deformation and basal sliding, thereby eroding the surface it over-rides. According to theory, an ice sheet becomes warm-based when the geothermal heat flux and internal heating by viscous dissipation provide enough heat to melt the base of the ice sheet. while the overlying ice mass insulates the base against the very cold air at the surface (Paterson, 1994).

Determination of the basal conditions of ice sheets is of paramount importance for the reconstruction of their topography and flow characteristics. Mac.Aveal (1993a,b suggested that a periodic change in basal conditions of the Laurentide ice sheet from cold- to warm-based could result in a dramatic thinning of the ice sheet and a massive outflow of icebergs into the North Atlantic Ocean.

The thermodynamic equations for ice divides have been analyzed by Grigoryan and others (1976). Grigoryan and others, as well as most previous ice-sheet modelers (c.g. Hooke, 1977: Jenssen, 1977; Sugden, 1977) analyzed a steady-state temperature field, as this allows great simplification of the governing equations. A number of studies have examined the effect of climatic change on ice sheets but in all cases the ice-sheet thickness is more or less constant (e.g. Greuell and Oerlemans, 1989; Firestone and others, 1990; Letréguilly and others, 1991; Oerlemans, 1991; Huybrechts, 1994). Most of these studies examine the Greenland ice sheet, which has persisted throughout numerous glacial cycles. However, models with a steady-state temperature distribution or a constant thickness are unrealistic for the continental ice sheets of the last glaciation, which persisted only for relatively short periods of time $50000-100000$ years. The thermal diffusion time $\left(t_{\mathrm{D}} \approx L^{2} / \kappa \approx\left(10^{7} \mathrm{~m}^{2}\right) /\left(10^{-6} \mathrm{~m}^{2} / \mathrm{s}\right)=\right.$ $10^{13} \mathrm{~s} \approx 3 \times 10^{5}$ years; with $L$ the ice-sheet thickness and $\kappa$ the thermal diffusivity of ice is on the same order as the lifespan of these ice sheets.

We use a finite-difference analysis to simulate the temperature profile at the center of an ice sheet throughout the course of a glaciation. At the center of the ice sheet, horizontal flow does not exist, thus simplifying our calculations to a one-dimensional model.

\section{MODEL}

The evolution of the thermal profile in a growing ice sheet is modeled as a one-dimensional, transient process. The governing equations are given in the Appendix. The model accounts for conduction in both the ice and the underlying rock, as well as advective transport in the ice due to the downward motion of accumulating material. The thermal conductivity and heat capacity of the ice are allowed to depend upon temperature although this nonlinearity proves to have a minimal effect in the present case), while those characteristic of the rock are assumed to be uniform and constant. To model the radial outward flow of ice in the central region of the ice sheet, the advective velocity of the ice varies from a specified value at the upper surface to zero at the base of the ice sheet. Rather than using a linear decrease in velocity Nye, $1951,1957,1963)$, we used the more realistic (personal 
communication from E. Waddington, 1995) model of Dansgaard and Johnsen (1969), in which the vertical velocity decreases linearly through the upper threequarters of the ice sheet and then quadratically to the base. This accounts approximately for the lack of basal sliding in a cold-based ice sheet. Our model allows for a moving boundary at the top of the growing ice sheet; i.e. the time-dependent position of the boundary is specified as an input function. In our model, the moving boundary is specified independent of the downward advection, even though the two are related in real ice sheets. Our downward advection is the part of the total accumulation rate that is accommodated by divergent lateral flow in the ice sheet and therefore does not result in a thickening of the ice sheet.

At the start of a model run, the sub-surface temperatures are in equilibrium with the geothermal heat flux and a given ground-surface temperature. The geothermal heat flux is applied at a depth of $4000 \mathrm{~m}$. Model runs with different depths show that beyond $2000 \mathrm{~m}$ depth negligible changes in the temperature profiles in the ice are found. This observation is consistent with that of Ritz. (1987). Ice is deposited on the ground surface at the surface temperature. Subsequent ice is deposited at cooler temperatures, according to the adiabatic lapse rate, as the ice sheet grows in elevation. Our model uses an adiabatic lapse rate of $8 \mathrm{C} / 1000 \mathrm{~m}$, halfway between the values for dry and moisture-saturated air (Trewartha and Horn, 1980). The parameters used in the model are given in Table 1. The geothermal heat flux warms bedrock and ice until basal melting occurs at $-1.96^{\circ} \mathrm{C}$ for a $3000 \mathrm{~m}$ thick ice sheet).

The model does not account for the latent heat of the melting of permafrost. This effect would be small for substrates with low porosities, and therefore a small water content, such as bare granitic bedrock as occurs in the Canadian shield. Regionally, sedimentary rocks, soil cover, etc. may result in significant ice content, which would require considerable energy for the phase change from solid to liquid. Since we model the ice sheet at its center, we do not consider the frictional heat created by ice movement, which would warm the ice. Therefore, the model results are not applicable for areas with significant horizontal ice velocities.

\section{NUMERICAL ANALYSIS}

The model problem involves a moving boundary, which poses a challenge for many numerical schemes typically used in conduction heat transfer. In the present case, we employ a "front-fixing" method (e.g. Crank, 1984), in which a tranformation of the spatial coordinates fixes the moving boundary (see Appendix). Then the surfaceboundary condition can be applied at a fixed nodal point in the numerical analysis. The effect of this transformation is to introduce a new term in the governing equation that takes the form of an advective contribution to the transport, with the apparent velocity scaling with the rate of change of the boundary location.

The numerical analysis is carried out by the method of lines (MOL) (e.g. Schiesser, 1991). In this method, the spatial derivatives are discretized by a central finitedifference scheme, reducing the partial differential equation at each computational node to a first-order, ordinary differential equation (ODE) in time. Each ODE is coupled to the ODEs at adjacent nodes through the discretization of the spatial gradients. The entire array of coupled, non-linear ODEs is passed to a highly optimized solver that performs the time integration by a backward difference scheme. The code has been tested against various exact, analytical solutions and proves to maintain excellent accuracy.

\section{ESTIMATE OF THE TIME-SCALE UNTIL BASAL MELTING OCCURS}

Figure 1 shows the evolution of the temperature profile over time for a surface temperature of $-12.5^{\circ} \mathrm{C}$. Ice-sheet growth is exponential with fast growth at the inception and decreasing with time. The characteristic rise time is 6000 years i.e. at this time $63 \%$ of the final thickness has been reached) and the final ice-sheet thickness is $3000 \mathrm{~m}$. Note that at 0 years no ice sheet exists, while the ground surface is at $-12.5^{\circ} \mathrm{C}$, which is about the current temperature in central Labrador and around the northern part of Hudson Bay (Washburn, 1980). After 10000 years, the ice sheet has reached about $2400 \mathrm{~m}$ thickness and is still growing. The ice sheet between 2000 and $2500 \mathrm{~m}$ above

Table 1. Ranges of paramelers used to model ice-sheet lemperalures

\begin{tabular}{|c|c|c|}
\hline Parameter & Range & Reference model \\
\hline Surface temperature $\left({ }^{\circ} \mathrm{C}\right)$ & -20 to -7.5 & -12.5 \\
\hline Final ice-sheet thickness (m) & $1000-5000$ & 3000 \\
\hline Depth at which heat flux is applied (m) & 4000 & Fixed \\
\hline Geothermal heat flux $\left(\mathrm{W} \mathrm{m}^{2}\right)$ & 0.05 & Fixed \\
\hline Surface accumulation rate $\left(\mathrm{m}\right.$ year ${ }^{-1}$ ) & $0.00 \quad 0.075$ & 0.025 \\
\hline Rise time of ice sheet $\left(t_{\mathrm{r}}\right.$, year $)$ & $1-50000 ;$ linear or exponential & 6000 exponential \\
\hline Adiabatic lapse rate $\left(\mathrm{C} \mathrm{km}^{-1}\right)$ & 8 & Fixed \\
\hline Conductivity of ice $\left(\mathrm{W} \mathrm{m}^{-1} \mathrm{~K}^{1}\right)$ & $9.828 \exp [-0.0057(T+273.15)]$ & Fixed ( $T$ in ${ }^{\circ} \mathrm{C}$ ) (Ritz, 1987) \\
\hline Heat capacity of ice $\left(\mathrm{J} \mathrm{m}^{3} \mathrm{~K}^{-1}\right)$ & $1.936 \times 10^{6}+6.6 \times 10^{3} \mathrm{~T}$ & Fixed $\left(T\right.$ in $\left.{ }^{\circ} \mathrm{C}\right)($ Ritz, 1987$)$ \\
\hline Conductivity of rock $\left(\mathrm{W} \mathrm{m}^{-1} \mathrm{~K}^{-1}\right)$ & 2.5 & Fixed \\
\hline Heat capacity of rock $\left(\mathrm{J} \mathrm{m}^{3} \mathrm{~K}^{-1}\right)$ & $2.3 \times 10^{6}$ & Fixed \\
\hline
\end{tabular}




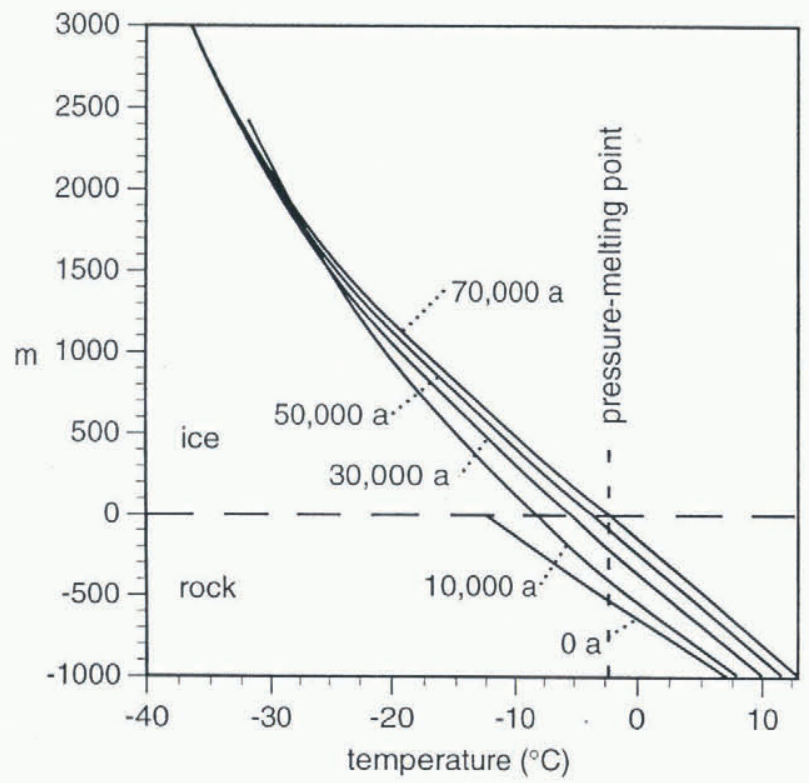

Fig. 1. Evolution of the temperature profile in an ice sheet. Initial surface temperature: $-12.5 \mathrm{C}$; final ice thickness: $3000 \mathrm{~m}$; downward advection: $0.025 \mathrm{ma}^{\prime}$; rise lime: 6000 a.

the original surface actually is cooled between 10000 years and 30000 years by downward advection of colder ice, while the temperature signal from the basal heating has not yet propagated to the surface. The basal melting point is reached after 72000 years. This model run will be used in all comparisons as a reference.

Figure 2 shows the change of the basal temperature over time for ice sheets with different initial surface temperatures and therefore initial ice and sub-surface temperatures). The warmer the ice and substrate, the more quickly the base melts. It is noteworthy that even with a relatively warm initial surface temperature of

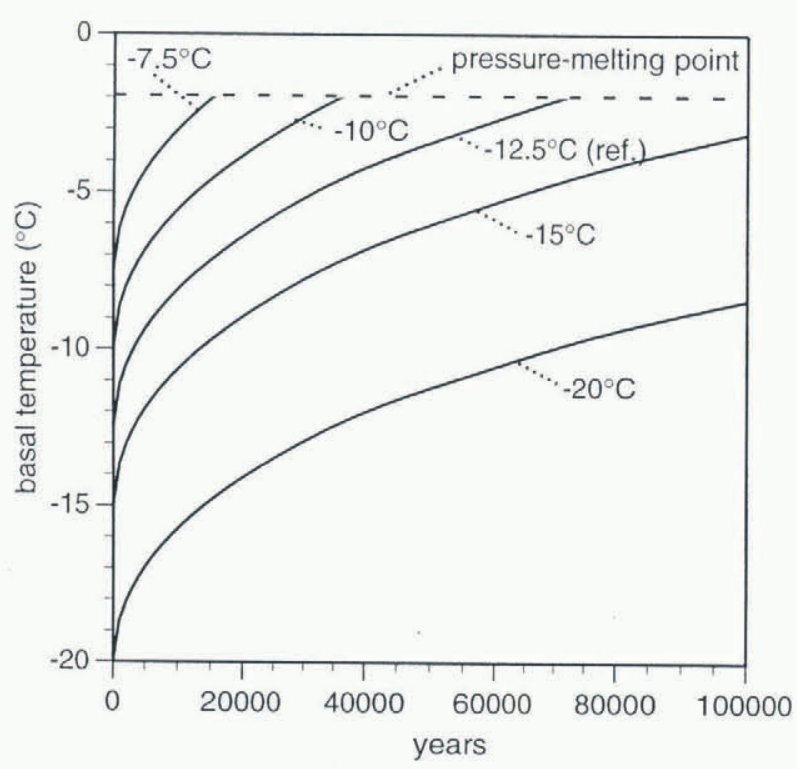

Fig. 2. Influence of initial surface lemperalure on basal lemperalures. Graph shows lemperature al ice/rock interface over time for different parameters. Final ice thickness: $3000 \mathrm{~m}$; downward advection: $0.025 \mathrm{ma}^{\prime}$; rise lime: $6000 a$.
$-7.5 \mathrm{C}$ basal melting does not occur until 15000 years after inception of the ice sheet. A temperature of $-7.5 \mathrm{C}$ may be unrealistically warm for the conditions at the inception of the Laurentide ice sheet, as this is considerably warmer than present ground temperatures. Hughes (1973) pointed out that the Laurentide ice sheet developed on permafrost and probably displayed relatively cold initial temperatures. An ice sheet with an initial surface temperature of $-15 \mathrm{C}$ remains cold-based throughout a 100000 year glacial cycle.

The influence of the final thickness of the ice sheet on basal temperatures is examined in Figure 3 . A thicker ice sheet provides more insulation, resulting in a warmer base. This factor is not important for ice sheets that are thicker than $2000 \mathrm{~m}$. An ice sheet thinner than $2000 \mathrm{~m}$ significantly extends the time until basal melting occurs. A $1000 \mathrm{~m}$ thick ice sheet under the given conditions probably would never become warm-based. Note that the pressure-melting point varies with ice-sheet thickness.

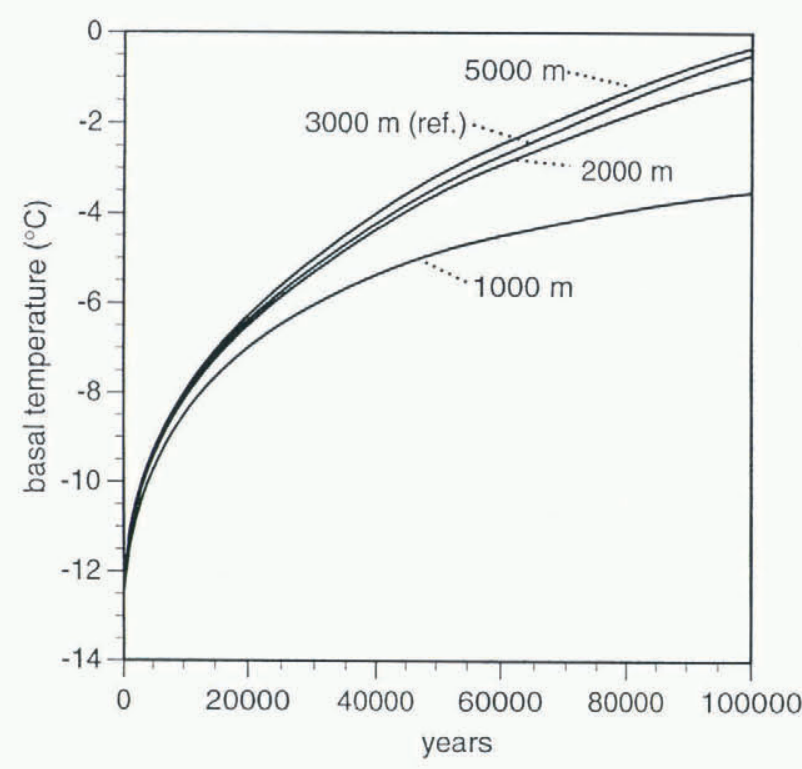

Fig. 3. Influence of final thickness of an ice sheet on basal temperalures. Nole that pressure-melling point varies with ice-sheet thickness. Initial surface temperature: $-12.5^{\circ} \mathrm{C}$; dow mard advection: $0.025 \mathrm{ma}^{\prime}$; rise lime: $6000 \mathrm{a}$.

Figure 4 shows the influence of downward advection of cold ice on basal temperatures. As ice is accumulated at the surface and flows out radially from the center of the ice sheet, the downward movement of cold ice cools the ice sheet. The values commonly assumed for downward advection at the center of the Laurentide ice sheet are between 0.025 and $0.05 \mathrm{ma}^{1}$ Sugden, 1977). Downward advection of ice significantly cools the base of the ice sheet. An ice sheet with a downward advection rate of $0.075 \mathrm{ma}^{-1}$ remains frozen to its bed for 240000 years.

The growth history of the ice sheet does not significantly influence the time at which basal melting occurs (Fig. 5). For the reference calculations, we used an exponential growth curve (see Appendix) with a large growth rate at the onset, decreasing exponentially as the ice sheet approaches its final thickness. We also tested a constant growth rate of the ice sheet until the final 


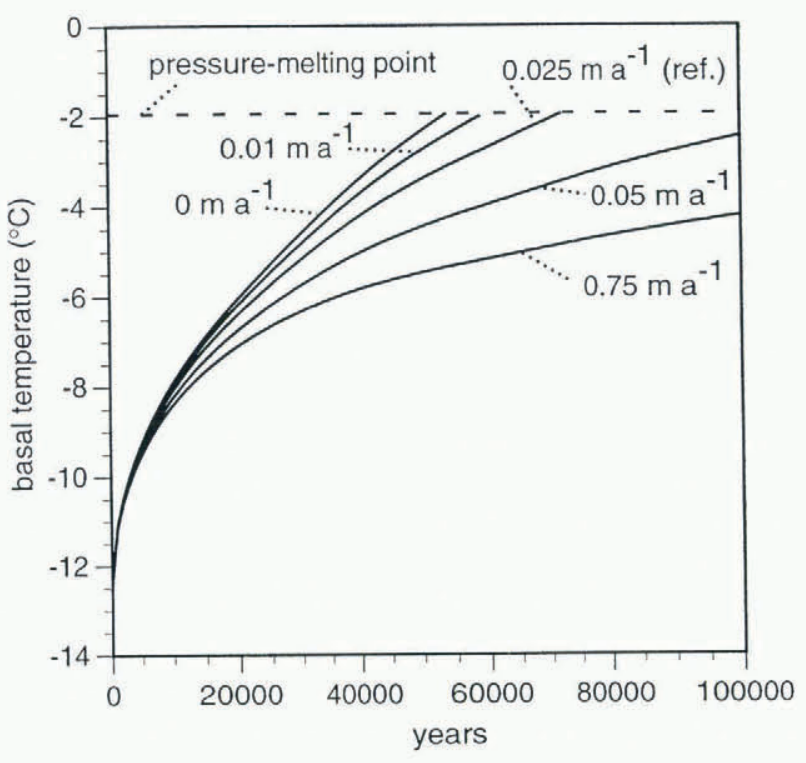

Fig. 4. Influence of downward advection on basal lemperature. Note that $0 \mathrm{ma}^{\prime}$ means no ice flow. Final ice thickness: $3000 \mathrm{~m}$, initial surface lemperalure: $12.5 \mathrm{C}$; rise lime: 6000 a.

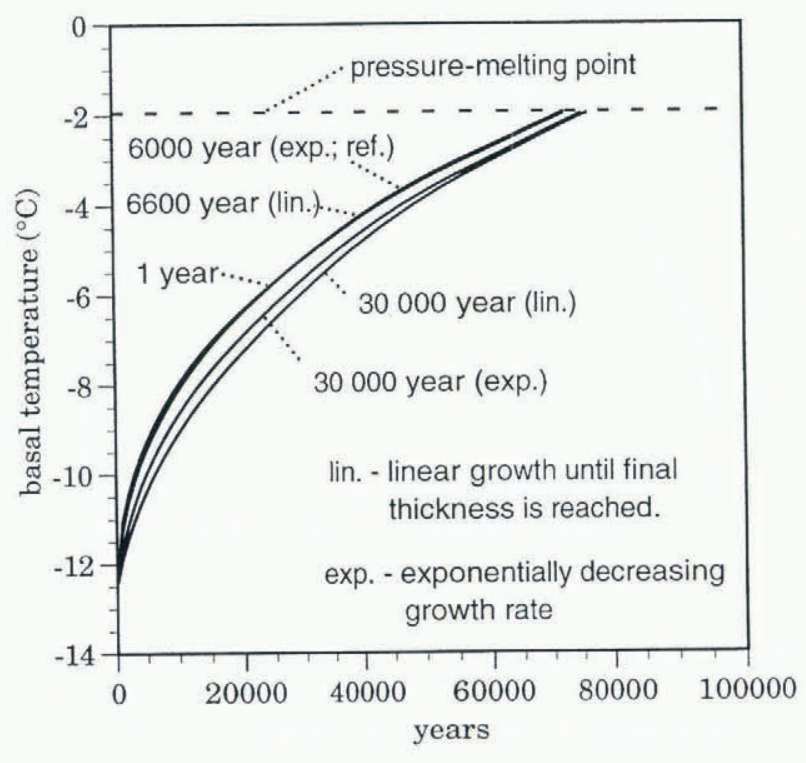

Fig. 5. Influence of the growth history of an ice sheet on basal temperatures. Examples of exponential and linear models (see Appendix) with various rise times shown. Note that in the model the rise lime is independent of downward advection. The curves for 1 a, 6000 a (exponential) and 10000 a (linear) are indistinguishable. Initial surface lemperature: $-12.5^{\circ} \mathrm{C}$; final ice thickness: $3000 \mathrm{~m}$; downward advection: $0.025 \mathrm{ma}^{-1}$.

thickness is reached and zero growth thereafter (linear growth). Calculations for linear growth over 10000 and 50000 years do not show large differences in the time at which basal melting occurs. The ice sheet seems to grow faster than the propagation of the temperature signal in the ice, so that the heat sink at the ice-sheet surface only weakly affects the basal temperatures. Therefore, the specifics of the ice-sheet growth history can be neglected to a certain degree when modeling the temperature history, as long as the ice-sheet growth does not affect downward advection. In real ice sheets, the accumulation rate determines both the growth rate and the rate of downward advection (Jóhannesson and others, 1989). As shown above, downward advection rates exert a strong influence on basal temperatures.

\section{RESULTS}

For ice sheets that disappear during interglacials, the model calculations show that the basal temperature is strongly time-dependent on the time-scale of a typical glacial cycle. Furthermore, heating due to the geothermal flux cannot account for basal melting at the center of an ice sheet during most or all of a glacial cycle if the initial ground temperature is colder than about $-10^{\circ} \mathrm{C}$. Basal melting at the center of an ice sheet may occur toward the end of a glacial cycle lasting $50000-100000$ years. Even under the most unfavorable conditions, the central part of an ice sheet takes tens of thousands of years to reach the pressure-melting point at the base. The basal temperature is determined mainly by the initial temperature of the surface (and substratum) and the advection of heat due to downward movement of ice. The thickness of the ice sheet does not influence the basal temperatures for values above $2000 \mathrm{~m}$. Our results show that the growth history of the ice sheet can be chosen freely without substantially affecting the results over the time-scale of interest, as long as there is no concurrent change in downward advection. This uncoupling of the growth history from the downward advection is unrealistic for real ice sheets but is a useful model assumption.

\section{DISCUSSION}

The central parts of the Pleistocene ice sheets probably were cold-based throughout a major part of a glacial cycle. Outward from the center, ice movement increases and therefore internal heating of the ice contributes to the thermal balance. Basal melting would first occur in areas of high ice velocity (ice streams, convergent flow between topographic obstacles), while other parts may never have reached the pressure-melting point. Therefore, we suggest that the basal conditions of the ice sheets were spatially heterogeneous and probably strongly influenced by topography. Exploration of these phenomena requires a two- or three-dimensional model which includes a transient thermal analysis.

Recent observations of preserved periglacial features in areas covered by the Fennoscandian ice sheet indicate that the ice sheet remained cold-based in places throughout its history Kleman, 1994; Kleman and Borgström, 1994). The patchiness of the formerly coldbased areas suggests that basal melting occurred only toward the end of the glaciation and that the preserved preglacial land forms are remnants of larger areas with cold-based conditions. In other areas, despite evidence for a warm-based ice sheet, these authors observed that erosion of preglacial features is much less than expected for a glacial cycle lasting tens of thousands of years. As indicated by our results, the ice sheet may have been cold- 
based during most of the glaciation, while basal melting occurred in some areas toward the end of the glacial cycle, resulting only in slight erosion before the ice sheet melted completely.

Lineations, striations and other features associated with basal sliding that are used to reconstruct the topography of former ice sheets (e.g. Shilts, 1980; Boulton and Clark, 1990) may have formed toward the end of the glaciation. Ice sheets reconstructed from these features may represent only the end of a glacial cycle. Alternatively, these features may have formed during earlier glaciations and have been preserved under a coldbased ice sheet.

A model of periodic basal melting and refreezing caused by thickening and thinning of the Laurentide ice sheet (so-called binge purge cycles) was proposed by MacAyeal $1993 \mathrm{a}, \mathrm{b})$ to explain periodic massive iceberg discharge into the North Atlantic Ocean Heinrich events). Our results do not contradict this model. Once basal melting occurs, the ice sheet can oscillate between cold- and warm-based conditions. The possible occurrence of Heinrich events during the early Wisconsin could indicate that Heinrich events originate in peripheral regions of the ice sheet, while the center remains coldbased. If the ice sheet in its entirety needs to be invoked to cause binge purge cycles, our model results suggest that these early events were not caused by binge purge cycles. On the other hand, the early Heinrich events could be interpreted as an indication that surface temperatures at the inception of the Laurentide ice sheet were warmer than $-7.5^{\circ} \mathrm{C}$ and that basal melting of the entire ice sheet occurred very early in the glacial cycle.

\section{ACKNOWLEDGEMENTS}

We thank B. Hallet and P. Clark for their comments and ideas on this project, as well as Zhilin Li and M. R. Baer for discussion of the numerical model. The comments of two anonymous reviewers, E. Waddington and D, MacAyeal were helpful to improve this paper.

\section{REFERENCES}

Boulton, G. S. and C. 1). Clark. 1990. A highly mobile Laurentide ice sheet revealed by satellite images of glacial lineations. Valure. $3466287,813-817$

Grank, J. 1984. Free and moving boundar problems. Oxford. Clarendon.

Dansgaard. W. and S.J. Johnsen. 1969. A flow model and a time scale for the ice core from Camp Century, Greenland. J. Gilaciol., 853 . $21.5-223$.

Firestone, J., E. Waddington and J. Cunningham. 1990. The potential for basal melting under Summit, Greenland. 7. Giaciol, 36123 . 163168.

Greuell, W. and J. Oerlemans, 1989. The evolution of the englacial temperature distribution in the superimposed ice zone of a polar ice cap during a summer season. In Oerlemans, J., ed. Gilacier fluctuation. and climatic change. Dordrecht, etc., Kluwer Academic Publishers, 289303.

Grigoryan, S. S., M.S. Krass and P.A. Shumskiy. 1976. Mathematical model of a three-dimensional non-isothermal glacier. \%. Glaciol.. $1777,401-417$.

Hooke, R. LeB. 1977. Basal temperatures in polar ice sheets: a qualitative review. Quat. Res., 7 1), 1-13.

Hughes, T. 1973. Glacial permafiost and Pleistocene ice ages. In Permafrost. Second Intemational Conference, 1328 July 197.3. lakutsk, C.S.S.R. Norlh American Contribution. Washington, DC, National
Academy of Sciences, 213-223.

Huybrechts, P. 1994. Present evolution of the Greenland ice sheet: an assessment by modelling. Global and Planetar) Change, 9 1-2), 39-51.

Jenssen, D. 1977. A three-dimensional polar ice-sheet model. J. Glaciol. $1880,373-389$.

Johannesson, T., C. Raymond and E. Waddington. 1989. Time-scale for adjustment of glaciers to changes in mass balance. 7 . Glaciol. $35121), 355369$.

Kleman, J. 1994. Preservation of landforms under ice sheets and ice caps. Geomorphology, 9, $19-32$.

Kleman, J. and I. Borgström. 1994. Glacial land forms indicative of a partly liozen bed. \%. Glaciol., 40 135). 255-264.

Letréguilly. A., N. Reeh and P. Huvbrechts. 1991. The Greenland ice sheet through the last glacial-interglacial cycle. Palaeogeogr.. Palaenclimatol., Palaevecol., 90 4), 385394.

Mac Ayeal, D. R. 1993a. A low-order model of the Heinrich event cycle. Paleoceanography, 86, 767773.

Mac.Ayeal, D. R. 1993b. Binge purge oscillations of the Laurentide ice sheet as a cause of the North Atlantic's Heinrich events. Paleoceanographr, 8 6), 775-784.

Nye, J.F. 1951. The flow of glaciers and ice-sheets as a problem in plasticity. Proc. R. Soc. London, Ser. A, 207 1091). 554572.

Nye, J. F. 1957. The distribution of stress and velocity in glaciers and icesheets. Proc, R. Soc. London, Ser. A. 239 1216. 113-133.

Nye, J.F. 1963. Correction factor for accumulation measured by the thickness of the annual layers in an ice sheet. F. Glaciol., 4 36), 785 788.

Oerlemans, J. 1991. The mass balance of the Greenland ice sheet: sensitivity to climate change as revealed by energy-balance modelling. Holocere, 1 1), $40-49$.

Paterson, W.S. B. 1994. The physies of glaciers. Third edition. Oxford. Elsevier.

Ritz. C. 1987. Time dependent boundary conditions for calculation of temperature fields in ice sheets. International Association of Hydrological Sciences Publication 170 Symposium at Vancouver 1987 The Phsical Basis of lee Sheet Modelling . 207216.

Schiesser. W.E. 1991. The mumerical method of limes: integration of partial differential equations. San Diego, C:A, etc., Academic Press.

Shils, W: W: 1980. Flow patterns in the central North American ice sheet. Vature, $2865770,213218$.

Sugden, D. E. 1977. Reconstruction of the morphology, dynamics and thermal characteristics of the Laturentide ice sheet at its maximum. Aret. Alp. Res.., $91,21-47$.

Trewartha, G. T. and I.. H. Horn. 1980. An intraduction to dimate. Fiffh edition. New York, etc., MeGraw-Hill.

Washburn. A. L. 1980. Ceocrology. New York, etc., John Wiley and Sons.

\section{APPENDIX}

\section{TRANSFORMATION OF THE GOVERNING EQUATION}

The one-dimensional energy balance considered is:

$$
\frac{\partial T}{\partial t}+w \frac{\partial T}{\partial z}=\frac{1}{\rho c} \frac{\partial}{\partial z}\left(k \frac{\partial T}{\partial z}\right)
$$

where $z$ is positive upward with its origin at the rock/ice interface, $w$ is the vertical velocity and both the heat capacity, $\rho c$, and the thermal conductivity, $k$, are, in general, functions of temperature. The heat flux at the base of the domain, located at some large depth $z=-h_{0}$, remains fixed at $q_{0}$ :

$$
\frac{\partial T}{\partial z}\left(-h_{0}, t\right)=-\frac{q_{0}}{k} .
$$

The upper boundary, or the ice/air interface, is located at $z=h$, where $h$ is an arbitrarily specified function of time. The surface temperature, $T_{s}$, is also an arbitrarily specified function of time: 


$$
T(h, t)=T_{\mathrm{s}}
$$

In the present case, the time-dependence of $T_{\mathrm{s}}$ is given indirectly through its dependence on $h(t)$.

The vertical velocity in the ice varies linearly through the upper three-quarters of the ice sheet and quadratically below that (Dansgaard and Johnsen, 1969):

$w=\left\{\begin{array}{cc}0, & -h_{0} \leq z<0 \text { (rock) } \\ -W \frac{(z / h)^{2}}{\left(z_{\mathrm{m}} / h\right)\left[2-\left(z_{\mathrm{m}} / h\right)\right]}, & 0 \leq z<z_{\mathrm{m}} \text { (lower ice sheet) } \\ -W \frac{2(z / h)-\left(z_{\mathrm{m}} / h\right)}{2-\left(z_{\mathrm{m}} / h\right)}, & z_{\mathrm{m}} \leq z \leq h \text { (upper ice sheet) }\end{array}\right.$

where $z_{\mathrm{m}}$ is the elevation above the bed at which the upper, linear velocity profile intersects the lower, quadratic profile. In all calculations shown in this paper, we take $z_{\mathrm{m}} / h=0.25$.) In the limit that $z_{\mathrm{m}} \rightarrow 0$, this recovers the linear profile of Nye $(1951,1957,1963)$. $W$ is the magnitude of the advective velocity at the surface. Here, $W$ is the volume flux of ice across the upper surface of the ice sheet, i.e. it represents the accumulation rate over and above that which goes into growth of the ice sheet. Of course, a divergent, lateral flow must balance the downward flow of ice. An assumption implicit in Equation $(\mathrm{A} 4)$ is that the velocity field in the ice is able to adjust rapidly to increasing $h$ in order to maintain $W$ in the form given throughout the growth history.

The "front-fixing" method entails a coordinate transformation $\zeta=z / h$, in terms of which Equation (Al) can be written for the domain within the ice
$(0 \leq \zeta \leq h)$ in the form:

$$
\frac{\partial T}{\partial t}+\left(-\frac{\zeta}{h} \frac{\mathrm{d} h}{\mathrm{~d} t}+\frac{w}{h}\right) \frac{\partial T}{\partial \zeta}=\frac{1}{\rho c h^{2}} \frac{\partial}{\partial \zeta}\left(k \frac{\partial T}{\partial \zeta}\right)
$$

where $w$ (Equation $(\mathbf{A} 4)$ is now written in terms of $\zeta$.

Note that, even in the absence of downward advection in the fixed reference frame $(w=0)$, the coordinate transformation has the effect of introducing into Equation (A5) an advection-like term that accounts for the moving boundary, $h(t)$. The effect of the boundary moving upward at velocity $\mathrm{d} h / \mathrm{d} t$ and that of advection of cold ice across the surface at velocity $-W$ are additive. The boundary condition at the top surface (Equation (A3)) is now applied at the fixed point $\zeta=1$, which is convenient for numerical implementation. In the scheme adopted here, we solve the conduction problem in the underlying rock domain $\left(-h_{0} \leq z \leq 0\right)$ in the untransformed coordinate, $z$, while solving Equation (A.5) for the ice. The temperature and heat flux are matched at the rock/ ice interface, $z=\zeta=0$.

We consider two particular forms of the growth function, $h(t)$ :

$$
\begin{aligned}
& h(t)=h_{\infty}\left[1-\exp \left(-t / t_{\mathrm{r}}\right)\right] \\
& h(t)=\left\{\begin{array}{cl}
h_{\infty} \frac{t}{t_{\mathrm{r}}}, & t \leq t_{\mathrm{r}} \\
h_{\infty}, & t>t_{\mathrm{r}}
\end{array}\right.
\end{aligned}
$$

where $h_{\infty}$ is the final ice thickness and $t_{\mathrm{r}}$ the rise time. In the text, we refer to Equation $(\mathrm{A} 6)$ as an exponential growth model and Equation (A7) as a linear model. 